\title{
Urban conservation of the historic city of Jugol, Ethiopia: a syntactic approach
}

\author{
H. Khali1 ${ }^{1}$, E. Bileha ${ }^{2}$ \& H. Mortada ${ }^{2}$ \\ ${ }^{1}$ The British University in Egypt, Egypt \\ ${ }^{2}$ King Abdul Aziz University, Saudi Arabia
}

\begin{abstract}
Jugol is an ancient African Islamic city. Due to its distinguished architectural and urban character that constitutes a unique blend of Islamic culture and African traditions, it was recently enlisted in the world heritage list. Currently, the city is suffering from a number of problems including poverty, congestion, isolation, weak accessibility, and environmental degradation. The current study is an attempt to mitigate the isolation and lack of accessibility problems utilizing space syntax as an analytical technique and design support tool. Isolation and lack of accessibility were found related to the changes in city's structure, recent expansion of the city outside the fence towards west, resulting in a shift of the city's integration core towards the west, thus weakening city's accessibility. A number of alternatives were tested and the alternative that improves the city's accessibility and alleviates its isolation was identified.
\end{abstract}

Keywords: Harar, Jugol, Ethiopia, Islamic heritage, space syntax, urban conservation, accessibility, connectivity, isolation.

\section{Introduction}

Harar is one of the most ancient historic Islamic cities in Africa. It is located in the south eastern part of Ethiopia. The city used to be one of the most important urban scientific and commercial centres in the east of Africa during ancient times, as it attracted scientists and scholars from different parts of the Islamic world. Harar's local name is "Jugol". It has a unique architecture style and urban pattern, a blend of Islamic culture and African traditions, a style unique enough to qualify the city to be on the International Council of Monuments and Sites (ICOMOS) list of world heritage cities. 


\section{Research problem}

Fierce changing tides threaten Jugol's unique architectural character and urban integrity as the city is suffering from poverty, congestion, environmental deterioration, isolation, and weak accessibility. Unfortunately, consecutive urban plans and conservation efforts did not succeed in alleviating these problems, particularly those related to the physical structure of the city, namely isolation and weak accessibility. Such problems threaten the liveability of the city and render conservation efforts ineffective. Research showed that these problems are interrelated, as Bird et al. [1], Vaughan et al. [2], and Peponis and Carpenter [3] found that poverty is related to isolation and lack of accessibility.

Failure to deal with these problems is partially due to the lack of proper analytical techniques capable of addressing the complexity of the spatial structure of the city.

Intervention into historic areas is a critical mission, as improper intervention may lead to loss of authenticity, meanwhile, lack of intervention may lead to decay of historic areas. Abada [4] identified five approaches for dealing with urban heritage: (a) the total protection approach, which advocates restoration of the historic built environment to its original state with no intervention; (b) the modernity approach, which regards heritage as an obstacle to evolution, which be demolished, if necessary; (c) the post modernity approach, which regards historic buildings as a source of inspiration for new designs; (d) the contemporary approach, which encourages interventions that would help achieve urban vitality, yet inflict no harm to the urban heritage; (e) the new shapes approach, which advocates mixing the old with the new, even if at odds with the traditional heritage.

Historic cities, the study argues, can adapt to limited gradual changes, yet cannot adapt to radical change, which would be as detrimental as no change, which would render them incapable of coping with necessities of modern life. Hence, the contemporary approach may be the approach most suitable for dealing with world heritage sites, as it respects urban heritage, yet tolerates justified interventions that are needed for the historic area to fulfil the necessities of modern life, given that such interventions do not harm the historic urbanism. The challenge is how to determine where, how, and to what extent to intervene in order to improve accessibility and reduce isolation.

The Vienna memorandum [5] acknowledged the need for methodologies and holistic approaches for urban conservation and development. Space syntax is one such approach; it is both a diagnostic tool and a decision support one. As a diagnostic tool, it identifies spots that have accessibility problems, at the level of single street segment, thus facilitates informed interventions in those locations. As a decision support tool, it allows prediction of consequences of suggested intervention, thus facilitates comparison of different alternatives, leading to selection of the optimum solution that would improve the city's accessibility and alleviate its isolation with minimal possible physical intervention in the historic area. 


\section{Research objectives}

The study aims to suggest specific physical interventions to improve Jugol's accessibility and to alleviate its isolation, informed by space syntax techniques of spatial analysis. Alleviating these problems is believed to be the key to achieving sustainable development of the historic city, which would help the city to regain its lost vitality and increase the success chances of future conservation efforts.

\section{Research methodology}

The study adopted a minimal intervention approach that utilizes space syntax. Space syntax is both a theory and spatial analytical techniques that is used to analyse the spatial relationships of various spatial systems using a number of objective measures.

The technique can simulate the performance of different existing, proposed spatial systems, and is thus considered a design support system. The technique is capable of dealing with different types of urban tissue whether ordered or spontaneous. Space syntax was utilized in a number of conservation studies. Trigueiro and Medeiros [6] investigated the changes to the integration core of Natal, historic city in Brazil and vitality of the city's streets and found a correlation between integration values and street vitality, as streets that exercised reduction in integration values that formerly had high integration value experienced decrease in their vitality. Han et al. [7] studied the development of Fuchin historic city to discover the conservation challenges and development opportunities. Karimi [8] utilized the technique in studying the changes that European and Islamic historic citied experiences under the pressures of modernization and argued that intervention that involve extensive changes to the spatial system cause irreversible damage to those cities that render conservation efforts useless. Karimi suggested a strategy that utilizes space syntax in comprehending the essence of the spatial logic of the historic city, facilitating informed conservation decision making that do not contradict with the essence and soul of the spatial system. A similar approach is used in the current study.

The urban structure of the city was analyzed using Depthmap software, to unveil Jugol's spatial structure, to identify its unique characteristics, to determine the impact of consecutive changes that the urban tissue had undergone during the last century, to determine their impact on the city's accessibility, to identify weakly connected areas. Depthmap was also used to test the impact of iterative modifications on accessibility, to identify the optimum intervention approach.

A number of alternatives were proposed and compared based on their contribution to improving the city's accessibility and connectivity with its surroundings, to reduce city's isolation.

Two abstract maps were produced for Jugol and its surroundings: an axial map and a segment map. Measures of integration and choice resulted from the analysis. These measures were consistently found to correlate with how people move around in an urban area (Hillier and Iida [9]). 
Integration is a measure of the relative depth of different spaces from all others in the graph (Hillier et al. [10]). High integration values indicate highly accessible spaces, while low values indicate segregated spaces. Studies showed that integration values alone are responsible for $65-80 \%$ of the variation in the movement of pedestrian traffic density along the streets, similar results were discovered regarding vehicular movements (Penn and Croxford [11]). Identifying the most accessible streets in the city, which is called "the integration core", is crucial to understanding urban systems.

Choice measures the degree of choice that each space represents for its immediate neighbours as a space to move to. Choice is a better predictor of movement for inhabitants that have better knowledge of the layout than strangers (Hillier et al. [10]). Choice is a good indicator of both pedestrian and vehicular traffic (Hillier [12]).

Intelligibility measures the ability to apprehend an urban system by moving around from one part to another (Hillier [13]). Intelligible systems have a value of 0.45 , while unintelligible systems have values around 0.2 .

\section{Status of conservation of the city of Harar}

Jugol has an area of 48 hectares. The city is surrounded by a stone wall from all directions. Jugol urbanism remained inside the fence until the end of the 19th century, after which, the city expanded outside the fence toward the west, establishing "New Harar". Yet, the historic city is still regarded as the cultural and religious centre of the entire city [14].

The city experienced considerable expansion. Fortunately, the urban tissue does not experience considerable alterations and the city has managed to retain its integrity and authenticity, until now. The city was subject to two alterations: first, widening the main east-west street, which fortunately improved the city's accessibility and promoted activities; second, the construction of the Italian Market, which negatively affected the city's accessibility. Fortunately, subsequent development plans only addressed Jugol's context rather than the city itself to evade spoiling its heritage.

Jugol has a compact fabric of a complex network of narrow winding streets and dead-end alleys. The city retained $90 \%$ of its urban fabric unchanged. Topography considerably affects the street pattern of the city, as some streets have staircases. The fence surrounding the city has five gates that open at radial streets, leading to the city centre.

Jugol suffers from a number of problems: 1 . Crowdedness, which negatively affected conservation efforts, as the inhabitants made modifications and encroachments that alter the urban pattern, and blocks some, thus reducing city's accessibility (Alessandri et al. [14]). 2. Isolation, as Jugol is suffering from relative isolation due to the fence that surrounds the city, and limits its connectivity with the surroundings, due to the city's expansion towards the west, which is gradually shifting the city centre outside Jugol and isolating the city, and due to the east-west corridor being the only connection with new Harar. 3. Weak accessibility, which is to some extent, characterized in many Islamic 
historical cities due to their narrow and crooked and dead-end streets, which is intentional for providing privacy for its dwellers. However, excessive use of dead-end streets hinders accessibility, particularly in cases of emergency like the need for an ambulance or firefighting. Encroachments on streets by residents worsen the situation. 4. Poverty; as Jugol is currently suffering from a spread of poverty due to a number of factors (Revault and Santelli [15]), among which is the city's loss of its regional commercial status as a result of altering the historic trade routes from Jugol to the nearby city of Dirdoa, and the city's relative isolation and weak accessibility. 5. Environmental deterioration, which led to a degraded condition of the majority of public spaces and the spread of humidity in houses (Atlabachew [16]).

During a field visit to the city, the researchers observed, listening to complaints, that the western part of the city is congested, that the eastern part of the city suffers from a lack of activities, and that the Italian market is decaying, as two thirds of its shops have closed.

The current study is concerned with problems related to isolation and accessibility. This study argues that informed interventions in certain locations, to relieve the city's relative isolation, to improve its accessibility, and to integrate it with the surroundings would eventually restore the city's vitality and improve its economy.

\section{Spatial analysis of Jugol's layout}

An analysis of Jugol's layout before and after alterations revealed the following:

First: the city has a relatively weak accessibility, with a low average integration value of 0.59 ; a bit lower than the average of 0.66 measured for 18 Arab cities by Hillier [17], yet, a bit higher than the average of 0.48 measured for six Iranian historic cities by Karimi [18]. This characteristic is intentional to make the movement of strangers through the city relatively difficult, except in certain streets, to preserve the privacy of the residential quarters.

Second: the integration core of the city (darker lines in figure 1) is compact and well distributed. The core included the main east-west street, around which most of the city's vital activities are grouped, a diagonal street that is running from the city centre toward south east, two smaller diagonals running north. Increasing the width of the main street actually improved the city's accessibility.

Third: introduction of the Italian market is the first most important physical change that had a negative impact on the city (figure 2), as it broke the continuity of the south-eastern diagonal, which significantly reduced its accessibility. This is quite noticeable from the fading of its colour. This change disturbed the integration core, which became less distributed, and more compact. This intervention reduced the mean integration of the entire city from 0.64 to 0.59 . Interestingly, the Italian Market itself suffers from a lack of accessibility that it initiated. The market is suffering from a closure of two thirds of its shops, which is believed to be due to its enclosed configuration as well as to the drop in the square's integration. 
Fourth: Jugol's expansion outside the fence, in one direction, the west direction, is the second most important change that affected Jugol. Such expansion reduced accessibility of the historic city even more, as the mean integration of Jugol dropped from 0.59 to 0.53 . More yet, the integration core seems to be moving away from the historic city toward New Harar, which has aggravated Jugol's isolation. Such imbalanced growth toward the west, if continued, would eventually lead to complete displacement of the integration core outside Jugol, which would be disastrous to Jugol's vitality.

Fifth: residential quarters of Jugol are situated in less accessible locations, between the radial streets. Street configuration in such areas represents a different spatial pattern, a pattern characterized by short, crooked segments with weak integration values. It can be noticed that integration values drop considerably as soon as one moves away from the integration core, which help keep strangers away from the residential areas. These quarters in general and the eastern quarters in particular are becoming more and more isolated due to the above mentioned changes, and by the encroachments on the public spaces which block some streets. This can be noticed in the colour fading of these areas.

Sixth: Jugol seems to have a spatial logic that raises accessibility of few main streets that connect the city to its surroundings from different directions, to attract and maintain major urban activities, meanwhile keeping residential quarters at low integration values to discourage strangers and protest their privacy. This logic seems to be changing, as the integration core no longer connects the city to the surroundings from all directions, as the south-eastern diagonal and the norther diagonals are becoming less accessible.

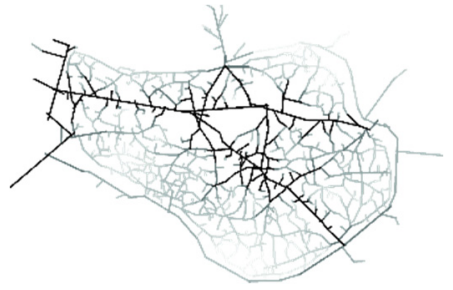

Figure 1: Jugol accessibility map before interventions.

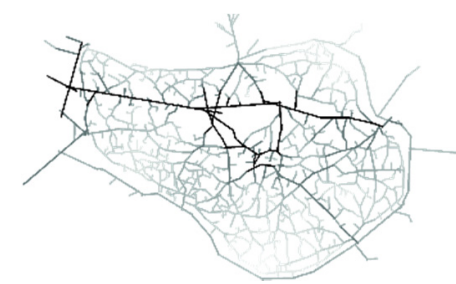

Figure 2: Jugol accessibility map after the Italian Market construction.

The previous analysis suggests that Jugol has a unique spatial logic by which densities of movement are regulated. That is, few main streets are prioritised by making them highly accessible, to encourage the mutual presence of both residents and strangers. These streets constitute the integration core. Meanwhile, the rest of the city's streets is kept exclusive for the residents, by reducing their accessibility and intelligibility to discourage strangers. This finding is in accordance with Hillier's [17] statement that strangers in Arab cities tend to be guided to certain public areas, whereas access to local areas is rendered difficult by the complexity of the axial structure.

Unfortunately, this subtle balance between the two realms of movement and presence is disturbed by the weakness of the core, which negatively affected the 
city's vitality, and by the excessive isolation of the residential quarters, resulting from the subsequent changes and encroachments that discourage local activities and commerce. Moreover, Jugol's connectivity with the rest of the city is also getting weaker as the western connection became the only link left between Jugol and the rest of the city of Harar (figures 2 and 3). The analysis suggests that a relationship does exist between the city structure, accessibility, and vitality, and that some physical interventions may have a damaging impact on cities.

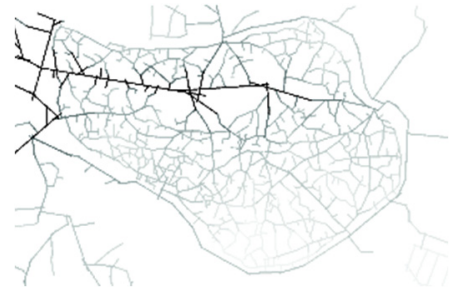

Figure 3: Jugol accessibility map after growth beyond the fence.

The analysis explained many of the observed problems including the congested western part of the city, lack of activities in the eastern part of the city, and the decaying Italian Market. The analysis revealed that these symptoms are outcomes of changes to the city's urban structure. These symptoms should be considered as warning signs, as the city would decay if no proper actions are taken to improve the city's accessibility and connectivity with its surroundings, and that Jugol would cease to exist as a city to live in, and would become a mere touristic site.

\section{Development of alternatives}

A number of alternatives that involve minimal interventions were suggested, evaluated, and compared, aiming to improve city's accessibility and connectivity with the new extensions. An iterative approach is followed where each alternative builds upon the previous one, trying to maximise its advantages and avoid its shortcomings.

The segment map of the existing situation (Figure 4) indicates the most important streets at city level (in bold black lines). The map showed that the only link between Jugol and the rest of the city is the east-west spine, which is also the most important street at city level. The map also showed a secondary ring to the north of the main spine to the west of Jugol, yet it does not pass through Jugol. The map also shows another, yet incomplete, southern ring. These two rings will constitute the starting point for strengthening Jugol's connection with its surroundings.

The first alternative: the only modification attempted at this stage was removing the Italian Market and reconnecting the east-southern diagonal. This modification led to a slight improvement in Jugol's accessibility, as the mean integration of Jugol increased from 0.53 to 0.56 . A more significant impact was 


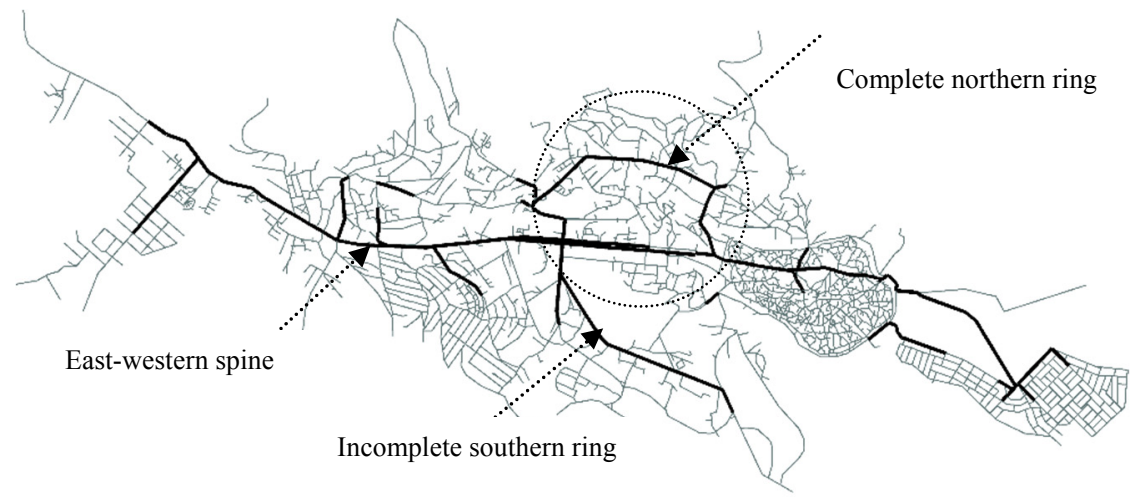

Figure 4: Segment map of the exiting situation showing that the east-west axis is the only link between the historic city and the extensions.

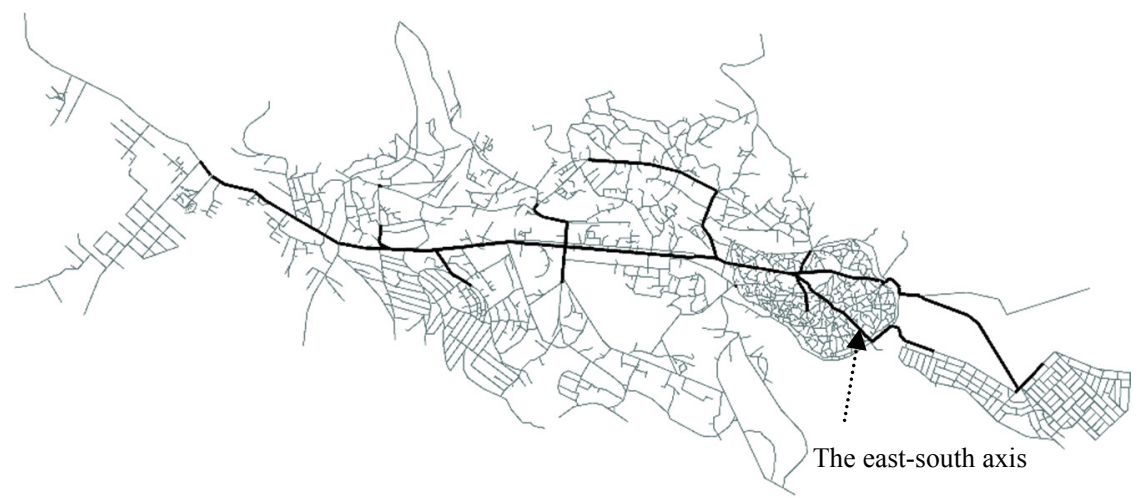

Figure 5: Segment map of the 1st alternative. The east-west axis still the only link between Jugol and New Harar. The east south axis is restored.

the restoration of the east-south axis, as it become part of the most important route network (as figure 5 shows). This alternative did not however create any new links with the rest of the city.

The second alternative: based on the 1st alternative, an attempt was made to link the ring road that surrounds Jugol with the northern and southern rings. Few street were added outside Jugol in order to create new links between Jugol and the rest of the city (Figure 6). This alternative succeeded in adding a northern link with the rest of the city, yet did not succeed to create a southern one. This alternative improved accessibility of Jugol from 0.54 to 0.59 , and improved accessibility of the whole city from 0.43 to 0.59 .

The third alternative: based on the second alternative, an attempt was made to create a southern link between Jugol and the rest of the city. As figure 6 indicates, the proposal succeeded in establishing a southern link between Jugol and New Harar. Moreover, it improved Jugol's accessibility to 0.6. 


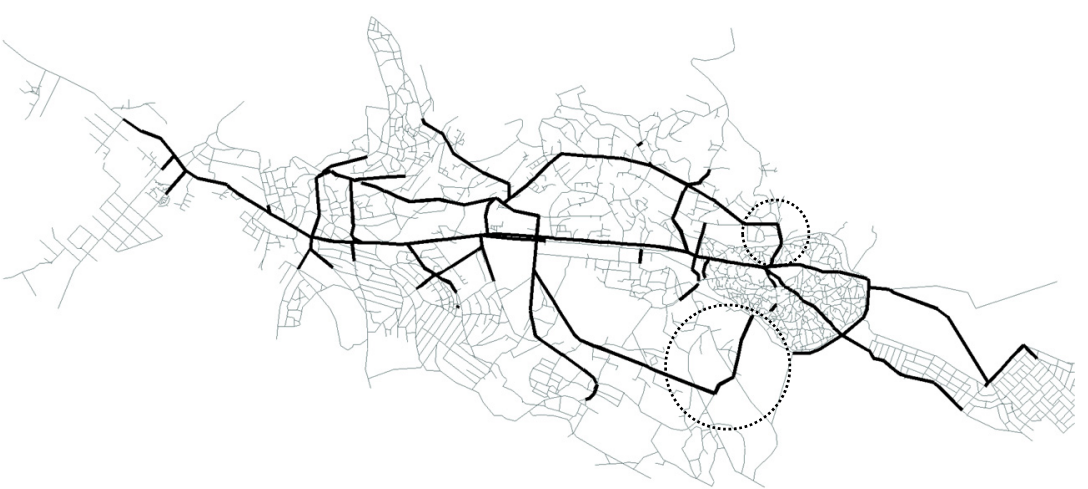

Figure 6: Segment map of the 2nd alternative showing a new link between Jugol and New Harar to the north, and an incomplete southern line.

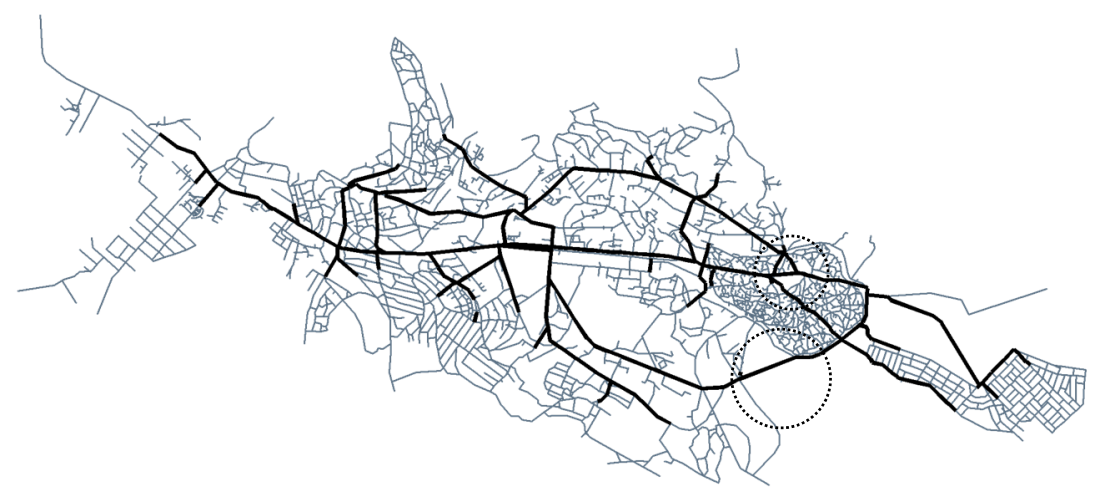

Figure 7: Segment map of the 3rd alternative, showing three links between Jugol and New Harar.

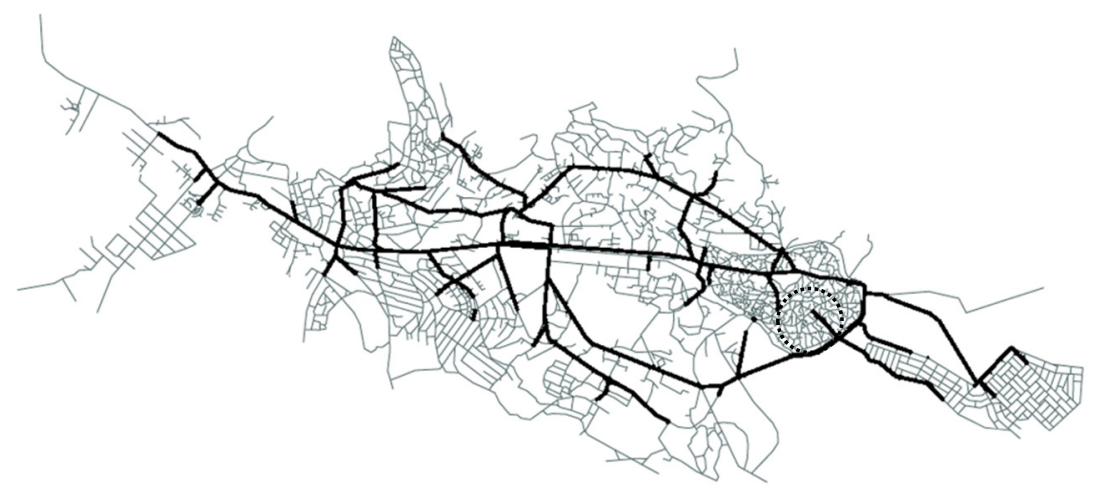

Figure 8: Segment map of the 4th alternative. This alternative is similar to the $3 \mathrm{rd}$, the only change is that the Italian market is preserved, resulting in loss of the east-southern axes. 
The fourth alternative is similar to the 3rd alternative, except that the Italian Market is preserved. It is quite clear that this action broke the east-southern axes, as figure 8 shows.

Table 1: Integration values of the existing situation and the proposed alternatives.

\begin{tabular}{|l|c|c|c|c|c|}
\hline & Existing & $\begin{array}{c}\text { 1st } \\
\text { option }\end{array}$ & $\begin{array}{c}\text { 2nd } \\
\text { option }\end{array}$ & $\begin{array}{c}\text { 3rd } \\
\text { option }\end{array}$ & $\begin{array}{c}4 \text { th } \\
\text { option }\end{array}$ \\
\hline Mean integration of Jugol & 0.54 & 0.56 & 0.59 & 0.6 & 0.6 \\
\hline Mean integration for new Harar & 0.53 & 0.55 & 0.59 & 0.6 & 0.6 \\
\hline Mean integration of the core & 0.78 & 0.75 & 0.82 & 0.82 & 0.81 \\
\hline
\end{tabular}

\section{Comparing the alternatives}

The four alternatives were compared with each other and with the existing situation, based on their ability to improve Jugol's accessibility and connectivity with its surroundings (Table 1). The results indicated that the first alternative had the least contribution to improving accessibility (integration value), and connectivity with the context. The three other alternatives have comparable integration values, yet the third alternative was found to be the best for the following reasons:

It connects Jugol to the rest of the city via three routes, the original east-west link, plus two other links; one to the north and the other to the south, and improves accessibility of the east-south axis. This alternative not only improved Jugol's accessibility by about $10 \%$, but also improved the accessibility of the whole city by about $12 \%$. This alternative did not disturb the internal structure of the historic city, as all suggested modifications are external ones, except for the proposed demolition of the Italian Market.

The Italian Market is a relatively recent addition (less than 100 years old). It does not follow the spatial logic of the city; it is decaying and preventing the extension of a rather important axis that would improve the city's accessibility, and it has no special architectural features. If demolition of the Italian Market is not preferred, then the second best alternative is the fourth alternative, which is similar to the third alternative in terms of connectivity with the rest of the city.

\section{Conclusion}

The study's main objective was to suggest physical interventions that would improve Jugol's accessibility and to alleviate its isolation, to help the city regain its lost vitality. The study identified the reasons behind the city's isolation and weak accessibility, particularly isolation of the east southern area of Jugol, and the deteriorating Italian Market, which were found to be due to the imbalanced growth towards the west, which is responsible for shifting the centre 
of activities towards the west, and the Italian Market that broke the important south-eastern axis.

The study suggested several alternatives, compared these alternatives and determined the optimum ones that would improve the city's accessibility and connectivity with the rest of the city, which would increase its liveability. The space syntax technique proved effective in dealing with problems of historic areas at the level of a street segment, which makes it a valuable tool for decision making, which would increase the success chances of future conservation efforts.

\section{Acknowledgements}

Depthmap software was developed by Alasdair Turner and Eva Friedrich, (2000-2011), University College London (UCL).

This research was funded by the Deanship of Scientific Research, King Abdul Aziz University, KSA.

\section{References}

[1] Bird, K, McKay, A., \& Shinyekwa, I. Isolation and poverty: The relationship between spatially differentiated access to goods and services and poverty. 2010.

[2] Vaughan, L. and Clark, D.L.C and Sahbaz, O. Space and Exclusion: The relationship between physical segregation, economic marginalisation and poverty in the city. In: van Nes, A, (ed.) (Proceedings) 5th International Space Syntax Symposium. (pp. 379-394). TU Delft, 2005.

[3] Peponis, J. and Carpenter, A. Poverty and connectivity. The Journal of Space Syntax. Vol. 1, No. 1. 2010.

[4] Abada, G. "Alseyaq Altareekhi: Tahqeeq Alhayawia Alomrania Men Khilal Altadakholat Altagdidiah" (in Arabic). The historic context: Achieving the urban vitality through renewal interventions. The $1 \mathrm{st}$ International Conference for Urban Heritage in the Islamic cities. Riyadh, May, 2010.

[5] ICOMOS Working Group, Vienna Memorandum on World Heritage and Contemporary Architecture - Managing the Historic Urban Landscape. Draft Revision. ICOMOS Working Group, Altaussee, 5-7 July, 2007.

[6] Trigueiro \& Medeiros, Marginal Heritage: Studying effects of change in spatial integration over land-use patterns and architectural conservation in the old town centre of Natal, Brazil. Proceedings of the 4th International Space Syntax Symposium, London, 2003.

[7] Han, Y., Jin-Yeu, T., \& Jiangang, L., Space Syntax Analysis of Foshan Street Network Transformation in Support Historic Area Redevelopment. The 4th International Conference of the International Forum on Urbanism (IFoU), Amsterdam/Delft, 2009.

[8] Karimi, K., The Spatial Logic of Organic Cities in Iran and the United Kingdom. Space Syntax First International Symposium, London, 1997. 
[9] Hillier \& Iida. Network and psychological effects in urban movement - an essential read. In: Cohn, A.G. and Mark, D.M., (eds.) Proceedings of Spatial Information Theory: International Conference, COSIT 2005.

[10] Hillier, B., Burdett, R., Peponis, J., \& Penn, A. Creating Life: or Does Architecture Determine Anything? Architecture et Comportment/ Architecture and Behavior 3, No. 3. pp. 233-250, 1987.

[11] Penn, A., and Croxford, D. Effects of Street Grid Configuration on Kerbside Concentrations of Vehicular Emissions. Space Syntax First International Symposium, London, 2007.

[12] Hillier, B. Using DepthMap for urban analysis: a simple guide on what to do once you have an analysable map in the system. M.Sc Advanced Architectural Studies 2007-8. UCL, 2008.

[13] Hillier, B. Space is the Machine: A Configurational Theory of Architecture. Cambridge University Press, 1996.

[14] Alessandri, R., Ammi, N., Bonnet-Chelhi, N., Bosredon, P., Greiner, E., Revault, P, and Santelli, S. Harar Jugol: Nomination of Properties for Inclusion on the World Heritage List. Harari People National Regional State City of Harar, Ethiopia \& Association Europeenne pour le Patrimoine Architectural et Urbain du Pourtour Mediterraneen, 2004.

[15] Revault \& Santelli. Harar: A Muslim City of Ethiopia. Maisonneuve \& Larose, 2004.

[16] Atlabachew, T. Tourism Development in Harar. Harar Revitalization Forum, 4-5 March, 2008. Harari Cultural Centre-Harar, Ethiopia, 2008.

[17] Hillier, B. A Theory of the City as Object: Or, How Spatial Laws Mediate the Social Construction of Urban Space. Proceedings of the 3rd International Space Syntax Symposium, Atlanta, 2001.

[18] Karimi, K., Urban Conservation and Spatial Transformations: Preserving the Fragments or Maintaining the 'Spatial Spirit'. Space Syntax Second International Symposium, Brasilia, 1999. 